\title{
CORRECTION
}

\section{Correction to: The role of information sharing on decision delay during multiteam disaster response}

\author{
Sara Waring ${ }^{1}$ (I) $\cdot$ Laurence Alison $^{1} \cdot$ Neil Shortland $^{1} \cdot$ Michael Humann $^{1}$
}

Published online: 8 October 2021

(c) Springer-Verlag London Ltd., part of Springer Nature 2021

\section{Correction to: \\ Cognition, Technology \& Work (2020) 22:263-279 https://doi.org/10.1007/s10111-019-00570-7}

This research was part funded by the Centre for Research and Evidence on Security Threats (ESRC Award: ES/ N009614/1), which is funded in part by the UK Home Office and security and intelligence agencies (see the public grant decision here: https://gtr.ukri.org/projects?ref=ES\% $2 \mathrm{FN} 009614 \% 2 \mathrm{~F} 1)$. The funding arrangements required this paper to be reviewed to ensure that its contents did not violate the Official Secrets Act nor disclose sensitive, classified and/or personal information.
Publisher's Note Springer Nature remains neutral with regard to jurisdictional claims in published maps and institutional affiliations.

The original article can be found online at https://doi.org/10.1007/ s10111-019-00570-7.

\section{Sara Waring}

S.K.Waring@liverpool.ac.uk

1 University of Liverpool, Liverpool, UK 